\title{
Penguatan Kapasitas UMKM di Tingkat Kalurahan: Pemberdayaan Masyarakat dengan Pengolahan Daun Kelor untuk Peningkatan Ekonomi Daerah
}

\author{
Strengthening of UMKM Capacity at Village Level: Community Empowerment with Moringa \\ Leaf Processing for Regional Economic Improvement \\ ${ }^{1)}$ Dian Aurelia Pramudita Insani \\ ${ }^{1)}$ Program Studi Ilmu Pemerintahan, Fakultas Ilmu Sosial dan Ilmu Politik \\ Universitas Muhammadiyah Yogyakarta \\ Jl. Brawijaya, Geblagan, Tamantirto, Kec. Kasihan, Bantul, Daerah Isimewa Yogyakarta \\ *email: dianaurelia@gmail.com \\ No hp: +62 85225443337
}

DOI:

10.30595/jppm.v5i1.12188

Histori Artikel:

Diajukan:

$10 / 11 / 2021$

Diterima:

$11 / 01 / 2022$

Diterbitkan:

18/02/2022

\section{ABSTRAK}

Permasalahan yang melatar belakangi penelitian ini adalah berkaitan dengan minimnya pemanfaatan potensi alam berupa daun kelor di Kalurahan Pilangrejo, Kabupaten Gunungkidul, Daerah Istimewa Yogyakarta. Berangkat dari kondisi tersebut Unit Kegiatan Mahasiswa (UKM) Kelompok Penelitian Mahasiswa (KPM) Universitas Muhammadiyah Yogyakarta (UMY) mengagas sebuah program Argoindustri Kelor Terintegrasi Berbasis Supply Chain Management (SCM). Kegiatan tersebut merupakan aktualisasi dari Program Holistik Pembinaan dan Pemberdayaan Desa (PHP2D) yang diselenggarakan oleh Direktorat Jenderal Pendidikan Tinggi (Ditjen Dikti), Kementerian Pendidikan dan Kebudayaan (Kemendikbud). Tujuan dari penelitian ini adalah mengkaji terkait proses pemberdayaan melalui program Agroindustri Kelor Terintegrasi Berbasis SCM yang dilakukan oleh UKM-KPM UMY terhadap UMKM di Kalurahan Pilangrejo dengan menggunakan konsep Green Economy. Selanjutnya, metode yang digunakan dalam penelitian ini adalah kualitatif dengan pendekatan studi kasus. Berkaitan dengan analisis data dalam penelitian ini menggunakan teknik interaktif model yang meliputi pengumpulan data, reduksi data, peyajian data, dan penarikan kesimpulan. Hasil dari penelitian ini menunjukkan bahwa pemberdayaan masyarakat melalui UMKM Agroindustri Handayani Kelor menciptakan suatu investasi serta peluang kerja dalam bidang ekonomi daerah yang berdampak pada meningkatnya Gross Domestic Product (GDP) melalui pemasaran produk hasil olahan daun kelor.

Kata kunci: UMKM; Agroindustri Handayani Kelor; Green Economy

\footnotetext{
ABSTRACT

The problem behind this research is related to the lack of utilization of natural potential in the form of moringa leaves in Kalurahan Pilangrejo, Gunungkidul Regency, Yogyakarta Special Region. Departing from these conditions, the Student Research Group (SME) Student Research Group (KPM) of the University of Muhammadiyah Yogyakarta (UMY) initiated an Integrated Moringa Argoindustry program based on Supply Chain Management (SCM). The activity is the actualization of the Holistic Program of Village Development and Empowerment (PHP2D) organized by the Directorate General of Higher Education (Ditjen Dikti), Ministry of Education and Culture (Kemendikbud). The purpose of this research is to examine the empowerment process through the SCM Integrated Moringa Agroindustry program conducted by UKM-KPM UMY against MSMEs in Kalurahan Pilangrejo using the concept of Green Economy. Furthermore, the method used in this study is
} 
Dian Aurelia Pramudita Insani

Penguatan Kapasitas UMKM di Tingkat Kalurahan: Pemberdayaan Masyarakat dengan Pengolahan Daun

Kelor untuk Peningkatan Ekonomi Daerah

qualitative with a case study approach. The data analysis in the study uses interactive model techniques that include data collection, data reduction, data presentation, and conclusion withdrawal. The results of this study show that community empowerment through MSMEs Agroindustry Handayani Kelor creates an investment and employment opportunities in the regional economy that have an impact on increasing Gross Domestic Product (GDP) through the marketing of moringa leaf processed products.

Keywords: UMKM; Agroindustri Handayani Kelor; Green Economy

\section{PENDAHULUAN}

Penelitian ini berangkat dari permasalahan mengenai minimnya optimalisasi untuk memanfaatkan daun kelor yang melimpah untuk meningkatkan perekonomian di Kalurahan Pilangrejo, Kabupaten Gunungkidul, Daerah Istimewa Yogyakarta (Rahayu, 2014). Melihat adanya potensi yang bisa dikembangkan di Kalurahan Pilangrejo melalui pemamfaatan daun kelor, kelompok mahasiswa dari Universitas Muhammadiyah Yogyakarta (UMY), melalui Unit Kegiatan Mahasiswa Kelompok Penelitian Mahasiswa (UKM-KPM) menggagas sebuah program Agroindustri Kelor Terintegrasi Berbasis Supply Chain Management (SCM). Kegiatan tersebut merupakan aktualisasi dari Program Holistik Pembinaan dan Pemberdayaan Desa (PHP2D) yang diselenggarakan oleh Direktorat Jenderal Pendidikan Tinggi (Ditjen Dikti), Kementerian Pendidikan dan Kebudayaan (Kemendikbud).

Program Agroindustri Kelor Terintegrasi Berbasis SCM yang diusung oleh UKM-KPM UMY, bertujuan untuk melakukan pemberdayaan dalam hal pemanfaatan daun kelor untuk dapat diproduksi menjadi tepung sebagai bahan baku makanan. Tidak hanya itu, proses pemasaran produk dengan melibatkan Usaha Mikro Kecil dan Menengah (UMKM) yang ada di Kalurahan Pilangrejo juga dilakukan. Lebih jauh lagi, implementasi dari program Agroindustri Kelor Terintegrasi Berbasis SCM yang diusung oleh UKM-KPM UMY merupakan bentuk pembangunan ekonomi yang ramah lingkungan atau termasuk dalam konsep Green Economy. Konsep Green Economy merupakan upaya pembangunan ekonomi dengan memberikan peningkatan kesejahteraan manusia dan kesetaraan sosial, sekaligus mengurangi risiko negatif yang akan merusak lingkungan secara signifikan (Cato,
2008). Sehingga luaran dari program tidak hanya menciptakan masyarakat yang produktif, mandiri, dan sejahtera namun juga ramah akan lingkungan.

Bedasarkan latar belakang yang telah diuraikan di atas, penelitian ini bertujuan untuk mengkaji proses pemberdayaan melalui program Agroindustri Kelor Terintegrasi Berbasis SCM yang dilakukan oleh UKMKPM UMY terhadap UMKM di Kalurahan Pilangrejo dengan menggunakan konsep Green Economy untuk meningkatkan perekonomian masyarakat di masa Pandemi COVID-19. Urgensi dari penelitian ini adalah untuk dijadikan referensi bagi kelompok mahasiswa untuk aktif menggagas program pemberdayaan masyarakat dengan fokus meningkatkan pengetahuan masyarakat terhadap potensi alam yang bisa dikembangkan di daerah. Sehingga dapat menciptakan masyarakat yang produktif, mandiri, dan sejahtera dengan memperhatikan konservasi lingkungan.

\section{METODE}

Penelitian ini menggunakan jenis penelitian kualitatif dengan pendekatan studi kasus. Dalam proses pengambilan data, peneliti telah melakukan pemetaan terhadap narasumber yang akan mendukung pengumpulan data primer pada penelitian dan sumber data sekunder yang juga akan mendukung analisis pada penelitian. Data primer diperoleh dengan melakukan wawancara dengan Ketua PHPD2 UMKM KPM UMY, Lurah Pilangrejo, Ketua Paguyuban UMKM Kalurahan Pilangrejo. Data sekunder diperoleh melalui studi pustaka pada dokumen terkait dengan PHP2D KPM UMY terkait dengan program pemberdayaan serta sumber lainnya yang berupa buku, artikel, dan berita digital. 
Dian Aurelia Pramudita Insani

Penguatan Kapasitas UMKM di Tingkat Kalurahan: Pemberdayaan Masyarakat dengan Pengolahan Daun

Kelor untuk Peningkatan Ekonomi Daerah

Analisis data yang digunakan adalah dengan menggunakan interaktif model (Yayat, 2017) yakni dengan reduksi data, penyeleksian data baik data primer dan data sekunder, penyajian data dalam bentuk dekrisisp naratif data, dan penarikan kesimpulan yang diperoleh dari temuan-temuan pada data primer dan data sekunder. Lokasi penelitian berada pada Kalurahan Pilangrejo untuk mengetahui peningkatan kapasitas UMKM Agroindustri Handayani Kelor.

Indikator dalam penelitian ini menggunakan konsep green economy UNEP (UNEP, 2009) yakni: 1) peningkatan investasi publik dan swasta, 2) peningkatan kualitas dan kuantitas pada lapangan kerja, 3) Peningkatan GDP, 4) penurunan penggunaan energi dan sumber daya ramah lingkungan, 5) penurunan polusi $\mathrm{CO}_{2}$, dan 6) penurunan konsumsi limbah produksi.

\section{HASIL DAN PEMBAHASAN}

1. Peningkatan investasi publik dan swasta Investasi publik dan swasta mempunyai peran yang dapat menentukan pertumbuhan suatu produksi ekonomi yang berimplikasi pada pertambahan modal (Hafriandi \& Gunawan, 2018). Oleh karenanya sektor investasi yang bersumber pada publik seperti halnya masyarakat, perusahaan, dan lembaga-lembaga lainnya memiliki harapan dapat memperoleh keuntungan atau profit. Investasi yang berbasis green economy juga mendorong terjadinya percepatan dari pertumbuhan hijau pada pembangunan berkelanjutan serta berpeluang untuk ekonomi baru (Hari Kristianto, 2020). Selain itu juga dorongan pada investasi berbasis green economy juga mengarah pada penciptaan teknologi serta konsumsi dan lapangan kerja.

Dalam realisasinya UMKM Agroindustri Handayani Kelor pada Kalurahan Pilangrejo melakukan beberapa hal untuk meningkatkan investasi publik dan swasta. Hal itu dilakukan dengan melakukan kolaborasi pada salah satu mitra terkait yang dalam hal ini Morica Cokelat Yogyakarta. Hal yang dilakukan adalah dengan melakukan kolaborasi berupa peningkatan agroindustri kelor yang memasuki pasar yang lebih besar. Selain itu bentuk kolaborasi tersebut juga memiliki proyeksi pada peningkatan investasi dari pihak eksternal dengan harapan untuk dapat keuntungan finansial yang lebih dibandingan dengan sebelum-sebelumnya.

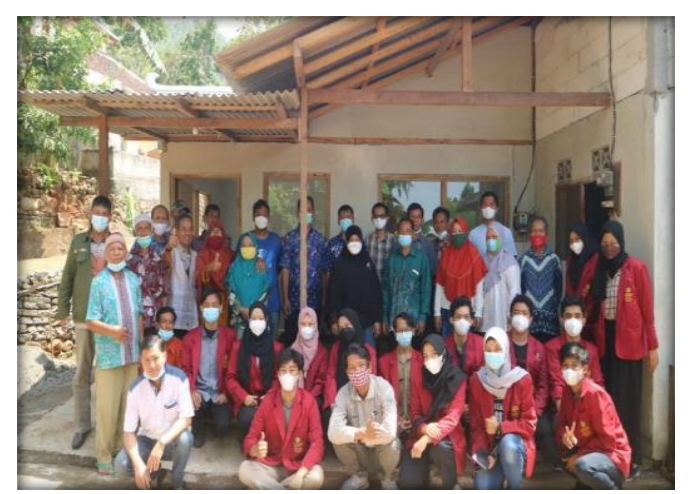

Gambar 1. Kolaborasi dengan mitra

2. Peningkatan kualitas dan kuantitas pada lapangan kerja

Peningkatan kualitas dan kuantitas pada lapangan kerja ditujukan untuk memperoleh daya saing yang tinggi serta kemampuan pada inovasi produk yang dapat menjadi minat pasar (Sriyono, 2018). Oleh karenanya penguatan pada kreatifitas dan produk inovasi ditujukan untuk membuat strategi pada penguatan produksi serta kelembagaannya. Selain itu juga perlu memperhatikan pilar-pilar lain seperti kelestarian lingkungan yang berbasiskan green economy agar tetap menjaga ekosistem lingkungan.

Pada temuan di lapangan Agroindustri Daun Kelor mempunyai beberapa fase pada peningkatan kuantitas dan kualitas lapangan kerja. Pertama, dalam meningkatkan kuantitas, Agroindustri Handayani Kelor melakukan aktivitas seperti halnya peningkatan serbuk kelor yang dilakukan dengan melakukan penanaman kembali pada proses pemanenan dengan tujuan untuk tetap meningkatkan produksi daun kelor. Selain itu dalam proses pembuatan kelor menjadi serbuk menggunakan mesin yang telah di modifikasi sehingga produksi serbuk kelor dapat lebih cepat dan efisien waktu. 


\section{Dian Aurelia Pramudita Insani}

Penguatan Kapasitas UMKM di Tingkat Kalurahan: Pemberdayaan Masyarakat dengan Pengolahan Daun

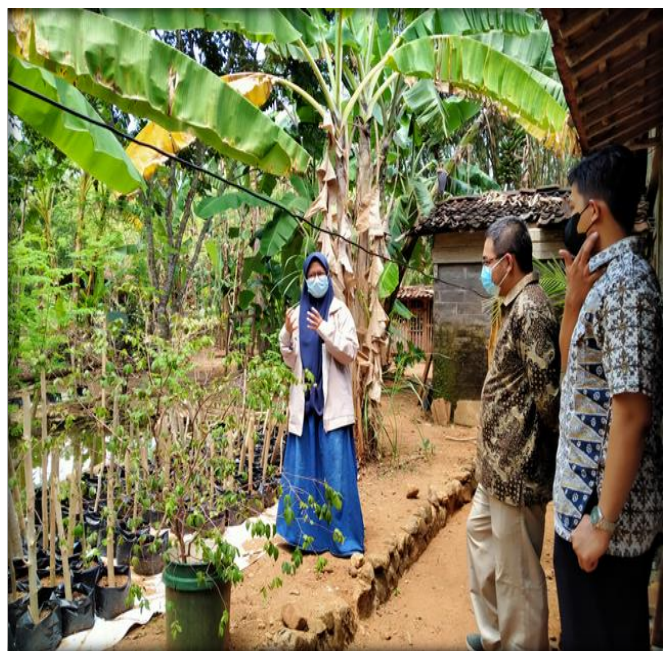

Gambar 2. Sosialisasi Standar Kebersihan

Kedua untuk meningkatkan kualitas produk, dalam proses produksi setiap pekerja yang masuk ke dalam rumah produksi diwajibkan menggunakan APD demi menjaga kebersihan dan kesterilan dari produk. Standar kebersihan menjadi prioritas utama bagi para pekerja untuk mewujudkan kualitas olahan hasil produksi daun kelor yang bersih dan higienis

\section{Peningkatan GDP}

Dalam meningkatkan daya saing UMKM, UMKM harus kompetitif dalam memaksimalkan keuntungan dan meminimalkan biaya produksi (Sumaryana, 2018). Persaingan ditentukan berdasarkan produk-produk yang diunggulkan oleh para pelaku UMKM. Hal itu bertujuan untuk meningkatkan pendapatan UMKM sehingga berimplikasi pada kesejahteraan pelakunya.

Pada Agroindustri Handayani Kelor ada beberapa inovasi yang sedang dikembangkan untuk meningkatkan GDP yakni dengan membuat olahan dari hasil produkasi kelor menjadi cookies kelor, bolu kelor, pudding kelor, dan mie kelor. Inovasi tersebut kemudian yang nanti akan dipasarkan pada masyarakat. Hal lain dibuatkanya beberapa inovasi produk tersebut adalah dapat memperoleh pendapatan yang tidak hanya bersumber dari satu produk saja.
4. Penurunan penggunaan energi dan sumber daya ramah lingkungan

Dalam mewujudkan penggunaan dan sumber daya ramah lingkungan maka perlu adanya inovasi yang tepat bagi para pelakunya khususnya para pelaku UMKM. Tujuannya adalah untuk memenuhii kelestarian ekosistem alam dan kehidupan manusia. Penggunaan energi dan sumber daya uang ramah lingkungan memiliki beberapa hal yang perlu diperhaikan : 1) sumber daya energi yang diperoleh berupa sumber daya yang dapat diperbarui, 2) sumberdaya energi yang digunakan harus berkelanjutan (Gusnita, 2010). Di Indonesia sendiri potensi-potensi tersebut saat ini masih jarang dimanfaatkan dan cenderung mengalami beberapa kendala-kendala (Sugiyono, 2004). Kendala-kendala tersebut diakibatkan oleh kurangnya penggembangan teknologi dan belum adanya kebijakan pada harga energi serta pengembangannya.

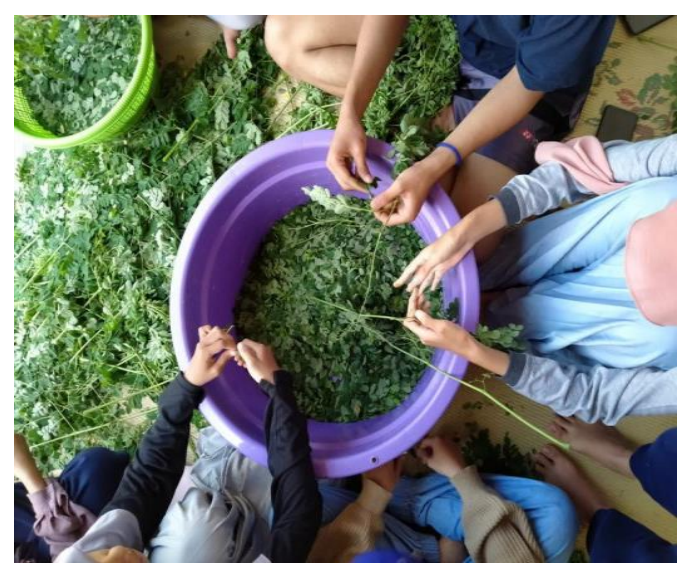

Gambar 3. Bahan Produksi Daun Kelor

Dalam proses produksi daun kelor sendiri memperoleh bahan material 100\% dari alam yang didapat melalui daun kelor. Dari tahapan awal sendiri proses penanaman sampai dengan pemanenan semuanya menggunakan bahan alami mulai dari penggunakan pupuk organik serta tanpa adanya campuran bahan kimia. Selain itu juga dalam untuk penyemprotan sendiri warga masyarakat sekitar juga menggunakan bahan organik dengan membuat ramuan-ramuan herbal yang 
bersumber dari tanaman maupun hewan. Tujuannya adalah tetap memperhatikan kualitas kelor yang dihasilkan sekaligus juga memperhatikan kelestarian lingkungan agar tidak tercemari oleh bahan-bahan yang bersumber dari kimia.

Kemudian dalam proses produksi Agroindustri Handayani Kelor dan para pekerjanya diproyeksikan tidak menggunakan mesin yang bersumber dari bakar akan tetapi menggunakan bantuan listrik untuk membantu proses produksinya. Selain tidak menimbulkan polusi udara dan mencemari lingkungan. Penggunaan alat bertenaga listrik tersebut juga memiliki tingkat kepratiksan dan kemudahan tersendiri dalam mengelola produksi daun kelornya

5. Penurunan polusi $\mathrm{CO}_{2}$

Penurunan emisi udara pada unit produksi merupakan upaya dalam mengurangi dampak dari global warming. Secara sosial-ekonomi dampak global warming sendiri memiliki implikasi seperti halnya 1) adanya gangguan terhadap kehidupan penduduk, 2) peningkatan risiko penyakit, 3) pengurangan lahan, 4) gangguan fungsi pada Kawasan pantai dan daerah pesisir, 5) gangguan pada sarana dan prasarana publik (Muryani, 2018).

Oleh karenanya dalam meminimalisir efek dari polusi $\mathrm{CO}_{2}$ Agroindustri Handayani Kelor memilih untuk tidak menggunakan mesin yang berbahan bakar. Akan tetapi lebih memilih pada penggunaan mesin listrik yang tidak menimbulkan emisi gas buang $\mathrm{CO}_{2}$ dan tentunya lebih ramah terhadap lingkungan. Selain itu juga produksi yang bermodelkan mesin listrik juga dapat memiliki tingkat efisiensi yang cukup tinggi jika dibandingkan dengan penggunaan mesin yang berbahan bakar. Efisisensi tersebut memiliki perbandingan yang cukup berbeda yakni sebesar $90 \%$.

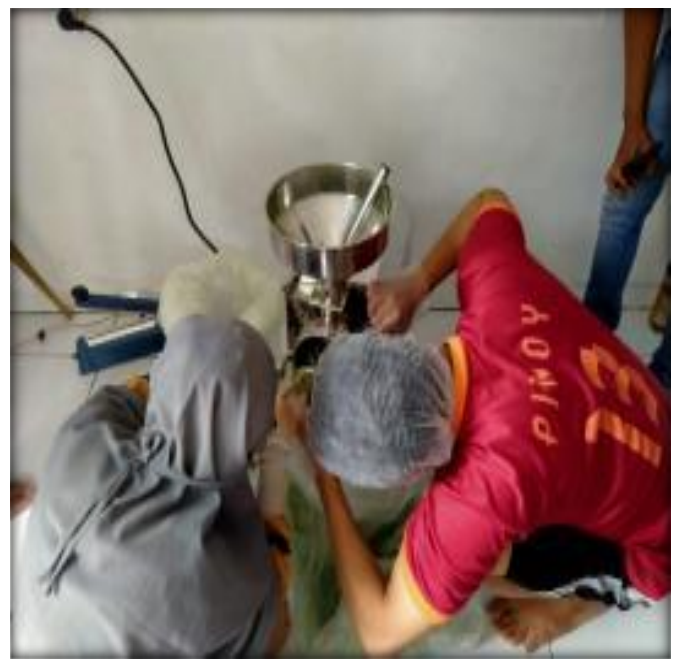

Gambar 4. Mesin Produksi

6. Penurunan konsumsi limbah produksi

Keberadaan limbah hasil produksi yang dibiarkan akan berimplikasi pada pencemaran lingkungan sekitar (Yana \& Badaruddin, 2017). Gangguan pada pencemaran lingkungan merupakan dampak yang ditimbulakan yang terjadi pada pencemaran tanah, udara, dan air. Kondisi tersebut memerlukan penanganan tersendiri yang cenderung bersifat ramah lingkungan.

Produk jadi yang dihasilkan yaitu serbuk daun kelor. Untuk mejaga kualitas serbuk kelor, produsen memilih mengemasnya dengan paper bag dibandingkan menggunakan plastik. Dalam suatu produksi pasti dihasilkan limbah hasil industri baik berupa padat, cair, dan gas memiliki potensi negatif terhadap lingkungan sekitar, oleh karena itu, pengolahan limbah hasil produksi merupakan salah satu komponen penting untuk menilai kelayakan suatu proses produksi (Nasir et al., 2015). Limbah daun kelor diolah kembali oleh masyarakat menjadi pakan ternak ataupun menjadi stek tanaman kelor baru yang dapat ditanam kembali untuk menjaga pelestariannya.

\section{SIMPULAN}

Jika ditinjau dari konsep green economy, program Agroindustri Kelor yang dilaksanakan oleh UKM KPM UMY terhadap UMKM Agroindustri Handayani memiliki dampak 
terhadap peningkatan investasi publik dan swasta. Hal ini dilakukan melalui kolaborasi bersama mitra terkait yang dalam hal ini Morica Cokelat Yogyakarta. Selanjutnya program ini juga membantu meningkatkan kualitas serta kuantitas pada lapangan kerja, hal ini tercermin dari salah satu upaya menjaga kualitas produksi dengan cara menggunakan APD demi menjaga kebersihan serta kesterilan produk.

Kemudian program ini juga meningkatkan GDP, hal ini tercermin dari yang dilakukan oleh Kalurahan Pilangrejo membuat hasil olahan kelor menjadi makanan jadi, seperti bolu kelor, cookies kelor, pudding kelor, dan mie kelor yang nanti akan dipasarkan. Hal itu bertujuan untuk meningkatkan pendapatan UMKM sehingga berimplikasi pada kesejahteraan pelakunya.

Dalam upaya produksi daun kelor yang dilakukan oleh Agroidustri Handayani menghasilkan sedikit emisi, pengolahan tanaman kelor diproduksi dengan menggunakan mesin listrik dibandingkan menggunakan mesin berbahan bakar dan bahan kimia. Penggunaan mesin listrik tidak berdampak besar bagi lingkungan karena tidak menghasilkan emisi gas $\mathrm{CO}_{2}$. Penggunaan mesin listrik dipilih sebagai bentuk kontribusi dalam upaya mengurangi dampak global warming. Hasil produk dari program ini yaitu serbuk kelor serbaguna yang dapat diolah kembali menjadi olahan makanan rumahan. Akhir dari proses produksi tanaman kelor juga menjadi perhatian khusus oleh Agroindustri Handayani Kelor. Limbah diolah kembali menjadi pakan ternak dan stek tanaman baru. Hal ini ditangani dengan baik untuk mengurangi limbah yang berpotensi mencemarkan lingkungan.

\section{DAFTAR PUSTAKA.}

Cato, M. S. (2008). Green Economics: An Introduction to Theory, Policy and Practice. Routledge.

Gusnita, D. (2010). Green Transport: Transportasi Ramah Lingkungan Dan Kontribusinya Dalam Mengurangi Polusi Udara. Berita Dirgantara, 11(2), 66-71.
Hafriandi, A., \& Gunawan, E. (2018). Pengaruh Investasi Publik dan Investasi Swasta Terhadap Pertumbuhan Ekonomi di Indonesia. Jurnal Ilmiah Mahasiswa, 3(3), 399-407. http://jim.unsyiah.ac.id/EKP/article/view/ 8949

Hari Kristianto, A. (2020). SUSTAINABLE DEVELOPMENT GOALS (SDGs) DALAM KONSEP GREEN ECONOMY UNTUK PERTUMBUHAN EKONOMI BERKUALITAS BERBASIS EKOLOGI. Business, Economics and Entrepreneurship, 2(1), 27-38. https://doi.org/10.46229/b.e.e..v2i1.134

Muryani. (2018). Produksi bersih dan model kerjasama sebagai upaya mitigasi emisi gas rumah kaca pada sektor industri. Dialektika, 13(1), 48-65.

Rahayu, E. (2014). Penentuan pusat-pusat pertumbuhan dalam pengembangan wilayah di kabupaten Gunungkidul.

Sriyono, S. (2018). Kemampuan Kinerja Keuangan Untuk Meningkatkan Daya Saing UKM Yang Berbasis Green Economy. Journal Competency of Business, 2(2), 84-105. https://doi.org/10.47200/jcob.v2i2.661

Sugiyono, A. (2004). Perubahan Paradigma Kebijakan Energi Menuju Pembangunan yang. Seminar Akademik Tahunan Ekonomi I, Pascasarjana FEUI \& ISEI, February, 1-12.

Sumaryana, F. D. (2018). Pengembangan Klaster Umkm Dalam Upaya Peningkatan Daya Saing Usaha. JISPO: Jurnal Ilmu Sosial Dan Ilmu Politik, 8(1), 58-68. http://journal.uinsgd.ac.id/index.php/jisp o/article/view/2771

UNEP. (2009). Global Green New Deal An Update for the G20 Pittsburgh Summit. 
Dian Aurelia Pramudita Insani

Penguatan Kapasitas UMKM di Tingkat Kalurahan: Pemberdayaan Masyarakat dengan Pengolahan Daun Kelor untuk Peningkatan Ekonomi Daerah

\section{UNEP}

Yana, S., \& Badaruddin. (2017). Pengelolaan Limbah Plastik Sebagai Upaya Pengurangan Pencemaran Lingkungan Melalui Transformasi Yang Memiliki Nilai Tambah Ekonomi. Serambi Engineering, II(4), 157-164.

Yayat, R. (2017). Kualitas Pelayanan Publik Bidang Administrasi Kependudukan Di Kecamatan Gamping. Jurnal Ilmiah Magister Ilmu Administrasi (JIMIA), 2, 56-65.

http://eprints.uny.ac.id/17523/1/SKRIPSI

FULL.pdf 